\title{
Antibacterial treatment of bacterial vaginosis: current and emerging therapies
}

This article was published in the following Dove Press journal:

International Journal of Women's Health

22 August 201I

Number of times this article has been viewed

\section{Jean-Pierre Menard}

Pôle Enfance et Famille, Conseil Général du Val-de-Marne, Créteil, France
Correspondence: Jean-Pierre Menard CPEF, 22 rue Gustave-Charpentier, 94240 L'Haÿ-les-Roses, France Tel +33 Ol 46875679

Fax +33 0I 56309623

Email Jean-pierre.Menard@cg94.fr

\begin{abstract}
Bacterial vaginosis is a common cause of malodorous vaginal discharge. It is also associated with sexually transmitted infections and adverse pregnancy outcomes. The magnitude of the gynecological and obstetrical consequences has stimulated therapeutic research and led to the testing of several therapies. The objective of this work is to present the currently available therapeutic strategies for the treatment of bacterial vaginosis and associated recommendations, and discuss the emerging therapies.
\end{abstract}

Keywords: bacterial vaginosis, treatment, emerging therapy

\section{Introduction}

Bacterial vaginosis (BV) is a common cause of malodorous vaginal discharge in women of reproductive age. ${ }^{1}$ Women's awareness of BV is low and often they self-medicate with antifungals before presenting very late when symptoms have become intolerable. However, many affected women are asymptomatic. ${ }^{1}$ The exact etiology remains elusive, although some authors have proposed a complex interaction between the numerous components of the vaginal microbial ecosystem and their human host. ${ }^{2}$ Multiple risk factors for BV infection have been hypothesized, including vaginal douching, African-American race, multiple or new sexual partners, and women who have sex with women. ${ }^{1,3}$ Inversely, hormonal contraceptive use, male circumcision, and consistent condom use reduce the incidence of $\mathrm{BV} .^{1,4,5}$

BV was first described in 1955 by Gardner and Dukes who reported a strong correlation between BV and the presence of Gardnerella vaginalis. ${ }^{6}$ However, progress in defining the composition of the vaginal microbiome had to await the development of new molecular techniques. These implicated not one bacterial species but numerous bacteria in BV and increased our understanding of the characteristic shift in the normal vaginal microbiota from a predominance of protective lactobacilli to pathogenic anaerobic bacteria. ${ }^{7}$ The resident Lactobacillus species are replaced by an overgrowth of vaginal anaerobes or Gram-negative bacteria including Gardnerella vaginalis, Atopobium vaginae, bacterial vaginosis-associated bacteria, Megasphaera species, Mycoplasma hominis, Mobiluncus species, Ureaplasma urealyticum, Prevotella, and Peptostreptococcus species. ${ }^{8}$ Moreover, BV-associated bacteria have been shown to form a prolific polymicrobial biofilm, the main component of which was found to be $G$. vaginalis and $A$. vaginae, that adheres to the vaginal epithelium. ${ }^{9}$ These recent advances have facilitated the detection and the identification of bacteria without the need for cultivation. Some of these bacteria have not previously been described or 
well characterized and have led some authors to propose new diagnostic tools based on molecular biological techniques. ${ }^{7,10}$ Nevertheless, the clinical Amsel criteria and the Gram stain-based Nugent score remain widely used. Clinical diagnosis is based on the combination of any three of the following four criteria: vaginal $\mathrm{pH}>4.5$, thin homogeneous vaginal discharge, clue cells on microscopic examination of vaginal fluid, and a "fishy" amine odor. ${ }^{11}$ A subjective clinical diagnosis is of limited value in assessing women in the general population as most of women with BV are asymptomatic. Microbiological diagnosis is based on Gram staining graded according to the Nugent score that reflects the presence of normal (score of $0-3$ ) or intermediate flora (score of 4-6), or BV (score of 7-10). ${ }^{12}$ The artificial category intermediate flora has further complicated the diagnostic approach since a considerable percentage of women tested fall into this category, the precise clinical implications of which, either none or pathology inducing, remain largely uncharacterized.

Interest in BV has grown since it was found to associate with an increased susceptibility to sexually transmitted infections, herpes simplex viruses, human papillomavirus, and human immunodeficiency virus (HIV). ${ }^{13,14} \mathrm{BV}$ has also been associated with postoperative infection and adverse pregnancy outcomes including premature rupture of membranes, premature labor and delivery, intra-amniotic infection, and low-birth-weight infants. ${ }^{15,16}$

The magnitude of these gynecological and obstetrical consequences has stimulated a research effort towards therapeutic development from which several therapies have been tested. However, evaluation of BV therapeutic studies reveals a major problem in that most used some or all of the clinical Amsel criteria, the Gram stain results, or a combination of both to define the diagnosis and the proposed cure, whereas a few others used the criteria defined by the US Food and Drug Administration (FDA) to perform the examination to evaluate the therapeutic response based on a combination of both the clinical outcome and the Gram stain results. ${ }^{17}$ Making comparisons between these studies is therefore problematic. The main aim here was to present the currently available therapeutic strategies for BV and their associated recommendations, as well as discuss the emerging therapies. For this review, I performed searches of MEDLINE (2000 to present) using the keywords "bacterial vaginosis", "treatment", "prevention", and "recurrent bacterial vaginosis" to identify all Englishlanguage articles concerning current and emerging therapies for BV. I observed the current guidelines published by the US Centers for Disease Control.

\section{Antibiotic therapy Metronidazole}

Metronidazole is a nitroimidazole antimicrobial agent used to manage protozoal infections such as trichomoniasis and anaerobic infections. ${ }^{18}$ Since the early 1980 s, metronidazole has been used widely in the treatment of BV with good clinical results. Various preparations allowing a vaginal or oral administration and different regimens have been studied.

\section{Metronidazole vs placebo}

Local (single-dose $100 \mathrm{mg}, 250 \mathrm{mg}$, and $500 \mathrm{mg}$ vaginal metronidazole tablets; or $0.75 \%$ metronidazole gel once or twice daily for 5 days) and oral metronidazole (400 mg twice daily for 7 days; or $500 \mathrm{mg}$ three times daily for 10 days) have lower rates of treatment failure compared with placebo. ${ }^{19,20}$ The cure rates of women given antibiotics were higher $(58 \%-100 \%)$ than the cure rates of women given placebo $(5 \%-29 \%)$ when evaluated 4 weeks after treatment. The cure rates varied widely according to the diagnostic criteria for abnormal flora at inclusion, the definition of cure and treatment failure, and length of time post-therapy before the follow-up visit.

\section{Routes of administration}

Two randomized controlled studies directly compared the efficacy of vaginal $(0.75 \%$ metronidazole vaginal gel $5 \mathrm{~g}$, twice daily for 5 days) vs oral regimens (500 $\mathrm{mg}$ twice daily for 7 days). The efficacy of vaginal and oral regimens was similar when evaluated 2 weeks and 5 weeks after treatment. ${ }^{21,22}$ However, the vaginal regimen was associated with less gastrointestinal complaints (33\% vs 52\%). ${ }^{21}$

\section{Duration of oral regimens}

In 1992, a meta-analysis was conducted on ten studies comparing different oral metronidazole regimens. ${ }^{23}$ The women were categorized according to the duration of oral metronidazole treatment: (1) $2 \mathrm{~g}$ single dose, (2) $2 \mathrm{~g}$ single dose daily for 2 days, (3) $400 \mathrm{mg}$ twice or three times daily for 5 days, (4) $500 \mathrm{mg}$ twice daily for 7 days. The cure rates ranged from $85 \%$ to $87 \%$ with no significant difference among the groups. Furthermore, no difference was found in the recurrence rates 1 month following single-dose, 5-day or 7-day regimens. The results of this meta-analysis were however criticized and in 1999, Joesoef and collaborators performed another meta-analysis including only the four studies that compared the single dose $(2 \mathrm{~g})$ and the 7-day regimens. They demonstrated that the clinical efficacy of 
the 7-day regimen is superior to the single-dose regimen with cumulative cure rates 3-4 weeks after completion of treatment of $82 \%$ for the 7 -day regimen vs $62 \%$ for the single-dose regimen. ${ }^{24} \mathrm{~A}$ more recent review also concluded that the 7-day regimen of metronidazole is superior to the single-dose regimen leading the authors to recommend it as the first-line regimen in the treatment of BV. More recently, a randomized trial examined whether extending the duration of metronidazole therapy to 14 days was superior to the 7-day regimen by enhancing the cure rates for BV. Cure rates were significantly improved with the 14-day regimen at the 7-day follow-up visit (45\% vs 63\%). However, the cure rates were equal at the 21-day follow-up visit, suggesting that relapse or reinfection had occurred..$^{25}$ Extending the duration of metronidazole therapy was not associated with an increase of vaginal candidiasis or of gastrointestinal adverse effects. ${ }^{25}$

\section{Adverse effects}

Metronidazole therapy is associated with side effects including gastrointestinal effects (metallic taste in the mouth, nausea, vomiting) and candida infection. However a recent meta-analysis did conclude that when applied topically, metronidazole was not significantly associated with candidiasis. ${ }^{20}$ Such side effects have been used to support single-dose therapy of oral metronidazole or topical metronidazole. ${ }^{26}$ They may also be responsible for difficulties adhering to a 7-day course of treatment and subsequently result in treatment failure. Incomplete cure would be associated with an increased risk of recurrence or the development of metronidazole resistance. Since vaginal regimens have been associated with fewer gastrointestinal complaints (33\% vs 52\%), ${ }^{21}$ vaginal metronidazole may be an alternative to oral metronidazole.

\section{Clindamycin}

Clindamycin is a second antimicrobial agent for the treatment of BV. This lincosamide antibiotic, a subclass of the larger family of macrolide antibiotics, has various treatment preparations including vaginal (ovule and cream) and oral.

\section{Clindamycin vs placebo}

In a recent meta-analysis, intravaginal treatment $(0.1 \%$, $1 \%, 2 \%$ clindamycin cream twice daily for 5 days; $2 \%$ clindamycin cream at bedtime for 7 days) showed benefits to BV treatment with lower treatment failure compared with placebo (relative risk: $0.25 ; 95 \%$ confidence interval: $0.16-0.37) .^{20}$

\section{Routes of administration}

Only one study has evaluated the use of oral clindamycin vs intravaginal administration. According to this study, oral administration of $450 \mathrm{mg}$ clindamycin three times daily and $2 \%$ clindamycin in vaginal cream $5 \mathrm{~g}$ once daily, for 7 days had similar cure rates. ${ }^{27}$

\section{Ovules vs cream}

One randomized study compared the efficacy of clindamycin vaginal ovules (100 mg daily for 3 days) with clindamycin vaginal cream ( $5 \mathrm{~g}$ at bedtime for 7 days) for the treatment of BV. ${ }^{28}$ The cure rates were similar: $53.7 \%$ for the ovule group and $47.8 \%$ for the cream group. Similarly, a single dose of clindamycin vaginal cream was found to be equivalent in terms of safety and efficacy to a 7-dose regimen of vaginal cream. ${ }^{29}$

\section{Clindamycin vs metronidazole}

In the recent Cochrane review, topical clindamycin $(2 \%$ clindamycin cream $5 \mathrm{~g}$ at bedtime for 7 days; ovule $100 \mathrm{mg}$ daily for 3 days) or oral clindamycin (500 mg twice daily for 7 days) appeared to be equivalent to oral (500 $\mathrm{mg}$ twice daily for 7 days $)$ or topical metronidazole $(0.75 \%$ gel $5 \mathrm{~g}$ daily for 7 days). ${ }^{20}$ However, topical clindamycin tended to cause a lower rate of adverse effects (metallic taste in the mouth, nausea, vomiting) than oral metronidazole. ${ }^{19}$ In addition, clindamycin cream and ovules which are oilbased might interfere with the safety of latex condoms and diaphragms.

\section{Tinidazole}

Tinidazole is a nitroimidazole antibiotic and an antiprotozoal agent that was first reported in Europe, Asia, and Latin America for its use in BV treatment. Trials evaluating oral regimens of 1-2 $\mathrm{g}$ daily for $1-5$ days have given favorable results. ${ }^{30}$ Tinidazole was licensed recently in the US for the treatment of $\mathrm{BV}^{31}$

\section{Tinidazole vs placebo}

A randomized controlled trial assessed the effectiveness, at 21-30 days after treatment, of tinidazole administered orally at $1 \mathrm{~g}$ once daily for 5 days and $2 \mathrm{~g}$ once daily for 2 days, compared with placebo. ${ }^{32}$ The authors demonstrated superior efficacy of both tinidazole regimens to placebo in the treatment of BV. The cure rates were $37 \%$ for the $1 \mathrm{~g}$ once daily for 5 days group, $27 \%$ for the $2 \mathrm{~g}$ once daily for 2 days group, and $5.1 \%$ in the placebo group. The FDA based its recent approval on these results. 


\section{Tinidazole vs metronidazole}

Based on its pharmacokinetic profile, tinidazole has the potential of being a highly efficacious drug for BV. Compared with metronidazole, it has a higher $\mathrm{C}_{\max }$, area under the curve, and steady-state serum concentration, and longer half-life. ${ }^{33}$ The spectrum of activity against bacteria associated with BV is very similar for the two agents. ${ }^{33}$ The efficacy of two regimens of tinidazole (500 mg twice daily or $1 \mathrm{~g}$ twice daily for 7 days) was compared with metronidazole $500 \mathrm{mg}$ twice daily for 7 days in a randomized trial. ${ }^{34}$ No significant difference was found in treatment failure rates (Nugent score $\geq 7$ ) between tinidazole $(27 \%$ for the $1 \mathrm{~g}$ regimen and $25 \%$ for the $500 \mathrm{mg}$ regimen) and metronidazole (18\%) at the 14-day follow-up visit. Similarly, short-term recurrence rates at the 2-month follow-up visit were not significantly different $(40 \%, 20 \%$, and $34 \%$ respectively).

\section{Tinidazole vs clindamycin}

Only one study has evaluated the efficacy of a single oral $2 \mathrm{~g}$ dose of tinidazole compared with $2 \%$ clindamycin vaginal cream for 7 days. ${ }^{35}$ At the end of the therapy, the women in the tinidazole group were treated with an acidic vaginal gel $2 \mathrm{~g}$ every 3 days for an additional 3 weeks. After 1 week of treatment, the clinical cure rate $(<2$ Amsel's criteria) was $84 \%$ in both groups with no statistical difference. At the 4-week follow-up the clinical cure rate was higher in the tinidazole and acidic vaginal gel group (94\%) than that in the clindamycin group (78\%) with no statistical difference. This result suggests that a single dose of oral tinidazole is as effective as topical clindamycin. No study has compared the efficacy of oral tinidazole with oral clindamycin.

\section{Adverse effects}

Oral tinidazole therapy has been associated with adverse events (yeast infection, nausea, vomiting, and bad taste in the mouth) such as those observed with oral metronidazole therapy. ${ }^{32}$

\section{Secnidazole}

Secnidazole is a nitroimidazole antibiotic with a broad spectrum of activity against anaerobic microorganisms and has a longer half-life than metronidazole. ${ }^{36}$ Used as a singledose oral regimen it appears effective in the treatment of amebiasis, giardiasis, trichomoniasis, and BV. ${ }^{36}$ It represents an attractive therapeutic option particularly in women whose likely compliance is doubtful.

\section{Secnidazole vs metronidazole}

No study has evaluated the efficacy of secnidazole compared with placebo. The efficacy of secnidazole was however compared with the mainstay of BV therapy, metronidazole. A randomized, double-blind, noninferiority study was conducted according to FDA guidance to compare the efficacy of a single $2 \mathrm{~g}$ oral dose of secnidazole compared with a 7-day course of $500 \mathrm{mg}$ metronidazole administered orally twice daily. ${ }^{37}$ The secnidazole regimen was shown to be at least as effective as the multiple-dose metronidazole regimen. The therapeutic cure at the 28-day follow up was $60 \%$ in the secnidazole group and $59 \%$ in the metronidazole group. Secnidazole was well tolerated and adverse events were similar in both groups ( $38 \%$ in the metronidazole group and $39 \%$ in the secnidazole group). Although headaches were rarely reported, they were more frequent in the secnidazole group ( $9 \%$ vs $4 \%$ ).

\section{Duration of oral regimens}

In an attempt to reduce adverse effects, one study was conducted to determine whether BV could be treated with a single $1 \mathrm{~g}$ oral dose of secnidazole with the same efficacy as that achieved with the conventional single $2 \mathrm{~g}$ oral dose. The women with symptomatic BV were randomized to receive one of the two regimens. ${ }^{38}$ The clinical cure rate was evaluated after 1 week based on Amsel's criteria. The cure rate was $97 \%$ using a $2 \mathrm{~g}$ therapy and $95 \%$ in the $1 \mathrm{~g}$ dose group. Adverse effects were reported at equal rates in both groups (34\% and $36 \%$ respectively).

\section{Other routes}

Narayana and collaborators developed and evaluated in vitro vaginal gels based on ion-activated systems for the local release of secnidazole. ${ }^{39}$ This new formulation showed promise for reducing the systemic side effects and improving the therapeutic effects and patient compliance.

\section{Nonantibiotic therapy Probiotics}

According to FDA and World Health Organization definitions, probiotics are "live microorganisms which when administered in adequate amounts confer a health benefit on the host". ${ }^{40}$ The mechanism by which probiotics confer such a health benefit is not well understood. Several hypotheses concerning their mechanism of action have been proposed: (i) as an example, Lactobacillus fermentum RC-14 has been reported to produce a biosurfactant containing a large number 
of collagen-binding proteins that could inhibit pathogen adhesion and induce a competitive exclusion of the pathogen on epithelial cells; (ii) probiotics may produce antimicrobial compounds such as hydrogen peroxide, lactic acid, or bacteriocin, which inhibit pathogen growth; (iii) probiotic therapy may cause a mucosal modulation that enhances the host immune system response. ${ }^{41-43}$

Microorganisms with probiotic properties are L. rhamnosus GR-1, L. rhamnosus Lcr 35, L. reuteri $\mathrm{RC}-14$, and L. crispatus CTV-05.44-47 Taken orally or vaginally these have been shown to improve vaginal flora without any side effects and are of potential clinical importance. ${ }^{44-47}$ Intestinal passage of probiotic has the advantage of interfering with the natural process by which pathogens emerge from the intestine and ascend along the perineum to the vagina. ${ }^{45}$

The newly recognized strains $L$. rhamnosus L60 and L. fermentum $\mathrm{L} 23^{48}$ have been considered for probiotics development due to their in vitro performance concerning bacteriocin production, adherence to epithelial cells, and coaggregation with pathogenic bacteria. ${ }^{48}$

\section{Treatment of BV}

Evidence of reduced levels of resident Lactobacillus species in BV has given rise to the concept of Lactobacillus strain replacement to restore the normal vaginal flora. Two recent reviews supported the use of probiotics, ${ }^{49,50}$ but further randomized controlled trials are needed before definitive conclusions can be made on the effectiveness of probiotics for the treatment of BV. One randomized study compared the efficacy of vaginal probiotics with vaginal metronidazole. ${ }^{51}$ The authors suggested that the cure rate of BV after two intravaginal capsules of probiotics containing $10^{9} \mathrm{~L}$. rhamnosus GR-1 and $10^{9}$ L. reuteri RC-14 daily at bedtime for 5 days was more effective than 0.75 metronidazole vaginal gel applied twice daily for 5 days. Symptomatic BV was significantly reduced at the 15-day follow-up in $85 \%$ of women in the probiotic group vs $45 \%$ in the metronidazole group. However, another recent randomized controlled trial comparing vaginal administration of $10^{7} \mathrm{~L}$. acidophilus and $0.03 \mathrm{mg}$ estriol with vaginal metronidazole suggested equivalent cure rates at 3-7 days of follow-up with slightly inferior results at 1-month follow-up. ${ }^{52}$ Other studies have associated antibiotics with probiotics, the results of which vary depending on the types of probiotics and antibiotics used and also according to route of administration (oral or vaginal). Oral metronidazole therapy (500 mg twice daily for 7 days) plus oral probiotic twice daily for 30 days ( 1 capsule containing $10^{9}$ L. rhamnosus GR-1 and $10^{9}$ L. reuteri RC-14) showed significantly increased efficacy compared with oral metronidazole alone. ${ }^{53}$ At the 30-day follow-up, 88\% had normal vaginal flora in the probiotic group compared with $40 \%$ in the placebo group. Martinez and collaborators confirmed that $L$. rhamnosus GR-1 and L. reuteri $\mathrm{RC}-14$ might provide an adjunct to antimicrobial treatment and improve cure rates. ${ }^{54}$ In a similar study design, a single dose of tinidazole ( $2 \mathrm{~g}$ ) supplemented with two capsules containing L. rhamnosus GR-1 and L. reuteri $\mathrm{RC}-14$ every morning for the next 4 weeks showed significantly increased efficacy compared with tinidazole alone. At the 28-day follow-up, $88 \%$ had normal vaginal flora in the probiotic group compared with $50 \%$ in the placebo group. This finding was not confirmed among HIV-infected women. ${ }^{55}$ Those with BV treated by metronidazole for 10 days ( $400 \mathrm{mg}$ administered orally twice daily), were randomized to receive daily oral capsules of probiotics L. rhamnosus GR-1 and L. reuteri RC-14 ( $2 \times 10^{9}$ viable organisms) or placebo for 6 months. No significant difference in the cure rate was found at the 2-week follow-up and the prevalence of BV was similar in both groups at 25 weeks of follow-up. This study therefore showed that BV is more difficult to eradicate in HIV patients and oral probiotic alone administered daily did not sufficiently improve the microbiota.

\section{Prevention of recurrence}

The second proposed use for probiotics is in preventing the recurrence of BV after an initial treatment. The hypothesis is that abnormalities of the vaginal flora often persist even in the absence of clinical symptoms after antimicrobial therapy.

One double-blind randomized placebo-controlled trial compared the efficacy of vaginal gelatine capsules $\left(10^{9}\right.$ L. gasseri Lba EB01-DSM 14869 and L. rhamnosus Lbp PB01-DSM 14870) administered for 10 days during three menstrual cycles with that of placebo adjunctive therapy after a 7 -day course of daily $2 \%$ clindamycin vaginal cream. ${ }^{56} \mathrm{At}$ 1 -month follow-up, the cure rate was $64 \%$ in the probiotic group and $78 \%$ in the placebo group; the difference was not significant. At the end of the study (6 months of follow-up) and for the women initially cured, $65 \%$ of the probiotic group had normal flora compared with $46 \%$ of the placebo group; the difference was significant. Vaginal probiotics inserted on 10 days per menstrual cycle over 3 months contributed significantly to the avoidance of relapse. The study showed that supplementary treatment of lactobacilli does not improve the efficacy of BV therapy during the 
first month of treatment, but for women initially cured, the adjunct treatment significantly lengthens the time to relapse. These results were confirmed in another study reporting the long-term administration of a vaginal probiotic. Women with symptomatic BV were randomized: (1) to receive twice daily oral metronidazole $500 \mathrm{mg}$ for 7 days; (2) to receive the same metronidazole regimen followed 8 days later by vaginal application of $40 \mathrm{mg}$ of L. rhamnosus $(>40,000$ colony forming units) once a week for 6 months. ${ }^{57}$ The follow-up over 12 months showed an increase in abnormal vaginal flora from $9 \% 1$ month after metronidazole alone to $31 \%$ at 12 months. In the probiotic group, the rate of abnormal flora was similar at the beginning and at the end of the follow-up (4\% and $9 \%$ respectively). According to the authors, this progressive divergence between the two groups resulted from the stabilization of a balanced vaginal flora in the probiotic group and the progressive increase in recurrence of BV in the group receiving metronidazole alone. The administration of the vaginal probiotic after oral metronidazole therapy may increase the cure rate during the follow-up period by stabilizing the vaginal ecosystem and thereby reducing the number of patients suffering BV recurrence.

Other authors have proposed the prophylactic use of probiotics in healthy women with a history of recurrent BV. A randomized, double-blind, placebo-controlled trial was conducted among healthy women who had suffered $>2 \mathrm{BV}$ episodes in the previous year. ${ }^{58}$ The women were randomized to receive either one vaginal capsule of probiotics ( 8 billion colony forming units of L. rhamnosus, L. acidophilus, and Streptococcus thermophilus) or placebo on a 7 days on, 7 days off, 7 days on regimen. Lower rates of BV incidence were reported during the 2 months after probiotic prophylaxis $(16 \%$ for the probiotic and $45 \%$ for the placebo group) according to Amsel's criteria. The 11-month follow-up consisting of a telephone interview suggested that women receiving probiotics had a lower incidence of BV symptoms than did those in the placebo group. Although this study was limited by the telephone follow-up interview that may have under-reported the frequency of BV symptoms, the results do suggest that local administration of Lactobacillus strain could therefore be a useful complementary tool in the management of recurrent BV. Other studies are now needed to validate further the efficacy of probiotics in the prevention of recurrent BV.

\section{Local acidification of vaginal fluid}

$\mathrm{BV}$ is characterized by the alkalinization of vaginal fluid (vaginal $\mathrm{pH}>4.5$ ) prompting some authors to propose correcting the vaginal $\mathrm{pH}$ in order to treat $\mathrm{BV}$. The results have been discordant. In two randomized double-blind clinical trials, vaginal acidification alone $(5 \mathrm{~mL}$ acetic acid gel intravaginally twice daily for 7 days or $5 \mathrm{~g}$ acid-buffering formulation gel intravaginally once daily for 5 days) was an ineffective therapy for BV compared with placebo or metronidazole. ${ }^{59,60}$ However, in another randomized study, the combination of oral metronidazole $500 \mathrm{mg}$ twice daily and $5 \mathrm{~g}$ lactic acid vaginal gel at bedtime for 7 days was found to be better than metronidazole alone at promoting lactobacilli colonization and reducing malodorous vaginal discharge. ${ }^{61}$ Moreover, not only was the lactic acid well tolerated but it also reduced recurrence of symptomatic BV ${ }^{61}$

\section{Emerging therapies Antibiotics and novel vaginal delivery systems}

Vaginal delivery of metronidazole or clindamycin is the most common therapy in the treatment of BV, but its efficacy is not optimal. Some authors are working towards improving existing formulations or creating new dosage forms. One group in Egypt working on pluronic polymers, has developed a hydrogel that swells in aqueous environments for use as a drug delivery system. This novel vaginal delivery system for metronidazole, improved the therapeutic efficacy compared with that achieved with conventional vaginal gel. ${ }^{62}$ In a pilot randomized trial, while similar cure rates were reported after 1 week of treatment ( $85 \%$ in the new vaginal gel group and $71.4 \%$ in the conventional vaginal gel group; $P=0.294$ ), the cure rate was significantly higher after 4 weeks in the new gel group compared with the conventional gel group (80\% and $47 \%$, respectively). These results suggest a novel and efficient long-term treatment of BV. Elsewhere, a new dosage form, containing metronidazole, was developed based on vaginal mucoadhesive tablets realized by including bioadhesive polymers. ${ }^{63}$ Similarly, new bioadhesive film formulations of clindamycin phosphate for vaginal delivery have also been developed. ${ }^{64}$ The in vitro properties and antibacterial activity of these new formulations may offer an alternative to traditional dosage forms for vaginal topical administration. The success of such new dosage forms, and bioadhesive products designed to extend the residence time of the antibiotic in the vaginal cavity, will not only depend on their effectiveness but also on their potential toxicity for epithelial cells of the vaginal mucosa and for resident lactobacilli.

\section{Novel antimicrobial agents}

Nifuratel, a furane-derivative, is an antiprotozoal and antifungal agent. Safe, well tolerated and with no known 
teratogenic effects, it can be used in the treatment of many infections of the genito-urinary tract. ${ }^{65}$ Togni and collaborators recently compared the antimicrobial activity of nifuratel against $G$. vaginalis, A. vaginae, and lactobacilli with that of the two currently used antibiotics. Results suggest that nifuratel has a more optimum spectrum of activity, being highly active against $G$. vaginalis and A. vaginae without affecting lactobacilli. ${ }^{66}$ These data are promising and led the authors to propose nifuratel for the treatment of BV. Clinical studies should now be developed.

\section{Effect of antifungal therapy on BV}

Self-treatment with antifungals is widely practiced and it may be useful in women with Candida who are co-infected with BV. The general consensus is that opposing vaginal $\mathrm{pH}$ are required for the growth of $C$. albicans and $\mathrm{BV}$, but because candida vulvo-vaginitis requires low acidity and $\mathrm{BV}$ requires high vaginal $\mathrm{pH}$ levels, this notion is incorrect. Indeed, Donders and collaborators reported recently that nine out of 142 women (roughly 6\%) with symptomatic candidosis also had BV. ${ }^{67}$ Antifungal treatment cured the BV in $70 \%$ of women with simultaneous candida vaginitis. While antifungal treatment may have a beneficial effect on women with concurrent $\mathrm{BV}$, it does not prevent $\mathrm{BV}$ from occurring in BV-negative women. A similar benefit of antifungal therapy has been reported previously in a randomized controlled trial, ${ }^{68}$ in which women who received ovules containing metronidazole and nystatin for $\mathrm{BV}$ had a better cure rate at 2 weeks of treatment than those receiving metronidazole $0.75 \%$ gel alone (20\% and $4 \%$, respectively). Moreover, the benefits of combined therapy remained at 3 months of treatment (52\% and 33\%, respectively).

\section{Antiseptics}

Essential oils from medicinal plants have strong antiseptic properties. Two recent studies have suggested the use of thymol and eugenol for BV therapy. ${ }^{69,70}$ Thymol is a natural monoterpene phenol found in oil of thyme, with an in vitro activity on $G$. vaginalis biofilms; and eugenol is a phenylpropene extracted in particular from clove oil. Both were applied via vaginal douche once daily for 7 days and resulted in a similar significant reduction in symptoms as that obtained with vaginal metronidazole..$^{70}$ Beyond reducing symptoms, the effect of thymol on vaginal flora should however be analyzed.

Glycerol monolaurate, another antiseptic, is a safe monoglyceride with bactericidal properties for Gram-positive organisms. It is microbicidal for Candida and G. vaginalis in vitro and reduces both organisms without affecting vaginal lactobacilli in vivo when applied via vaginal gel. ${ }^{71}$ Clinical trials are now needed to assess the effectiveness of glycerol monolaurate gel in treating BV.

A recent study evaluated the efficacy of octenidine hydrochloride/phenoxyethanol, a local antiseptic spray, applied for 7 or 14 days compared with 7 days of metronidazole vaginal tablets for BV therapy. ${ }^{72}$ The local antiseptic spray was as effective as the standard therapy with cure rates of $58 \%$ and $71 \%$ at 7 days and 14 days, respectively, compared with $61 \%$ at 7 days with metronidazole.

A team from China has developed a temperature-sensitive gel containing silver nanoparticles and investigated its antibacterial properties in vitro. This optimized silver nanoparticle dosage form demonstrated great potential, encouraging further development for the clinical treatment of $\mathrm{BV} .^{73}$

\section{Prebiotics}

Another alternative for treating $\mathrm{BV}$ is to induce a vaginal flora shift from a BV- to a Lactobacillus-dominated flora by promoting the growth of lactobacilli. The principle behind prebiotics is to provide nutriments that stimulate the growth of lactobacilli. Oligosaccharides can selectively promote the growth of lactobacilli that in turn generate lactic acid to lower the vaginal $\mathrm{pH}$ and secrete antibacterial substances that inhibit the adhesion and replication of the anaerobic bacteria. ${ }^{74}$ Some authors have proposed the topical application of a gel containing sucrose, a disaccharide of glucose and fructose, to treat BV. A Phase III clinical trial was conducted including women with symptomatic BV who were randomly assigned into three groups for vaginal application of sucrose $(5 \mathrm{~g})$, metronidazole $(0.75 \%)$, and placebo gels, twice daily for 5 consecutive days. ${ }^{75}$ The therapeutic cure rates (according to FDA guidelines) evaluated 21-35 days after the start of treatment were $61 \%, 67 \%$, and $7 \%$, respectively, for sucrose, metronidazole, and placebo gel groups. These results suggest that sucrose has a therapeutic cure rate similar to the metronidazole gel. Interestingly, at the intermediate visit (7-10 days after the start of treatment), the therapeutic cure rate was statistically higher for the sucrose group (83\%) than for the metronidazole group (71.3\%) and the placebo group $(0.9 \%)$. The evaluation of lactobacilli based on the Nugent score at the 5-7 days visit showed significantly higher levels of lactobacilli in the sucrose gel group compared with the metronidazole group. These results suggest that by promoting the growth of lactobacilli, sucrose gel restores normal vaginal flora more rapidly than does metronidazole. However, while the rate of adverse events after sucrose gel was found to be 
similar with that found in the other groups, treatment with sucrose would be expected also to promote the development of candidosis.

\section{Current strategies Symptomatic BV}

$\mathrm{BV}$ is the most prevalent cause of vaginal discharge or odor. The most recent recommendations for the treatment of symptomatic BV to relieve these vaginal symptoms were issued in 2010 by the US Centers for Disease Control. ${ }^{76}$ The recommended regimens in pregnant and nonpregnant women are reported in Table 1. First-line treatment includes metronidazole or clindamycin. Alcohol consumption should be avoided throughout the 7-day treatment with systemic metronidazole and 1 day after. For women presenting side effects, the vaginal route may be recommended. Choice of treatment should be carefully considered among users of condoms and diaphragms, since weakening of the latex can occur for up to 5 days after applying the oil-based clindamycin cream. Of note is the recent introduction of tinidazole as an alternative to metronidazole and clindamycin. During treatment regimens, women should be advised to avoid unprotected sex. In addition, vaginal douching that promotes vaginal recurrences should be discouraged. Routine treatment of sex partners is not considered necessary.

\section{Asymptomatic BV}

The benefits gained from screening asymptomatic BV in order to prevent adverse outcomes are doubtful. While the association between BV and preterm birth is well established, data are inconsistent on the screening and treatment of asymptomatic BV during pregnancy in order to prevent

Table I Regimens for the treatment of bacterial vaginosis according to the US Centers for Disease Control ${ }^{76}$

\begin{tabular}{l} 
Three recommended regimens \\
I. Metronidazole $500 \mathrm{mg}$ orally twice daily for 7 days \\
2. Metronidazole gel $0.75 \%$, I full application $(5 \mathrm{~g})$ intravaginally, once \\
daily for 5 days \\
3. Clindamycin cream $2 \%$, I full application $(5 \mathrm{~g})$ intravaginally at bedtime \\
for 7 days \\
Three alternative regimens \\
I. Tinidazole 2 g orally once daily for 2 days \\
2. Tinidazole I g orally once daily for 5 days \\
3. Clindamycin $300 \mathrm{mg}$ orally twice daily for 7 days \\
4. Clindamycin ovules 100 mg intravaginally once at bedtime for 3 days \\
Three recommended regimens for pregnant women \\
I. Metronidazole 500 mg orally twice daily for 7 days \\
2. Metronidazole 250 mg orally 3 times daily for 7 days \\
3. Clindamycin $300 \mathrm{mg}$ orally twice daily for 7 days \\
\hline
\end{tabular}

preterm birth. ${ }^{77}$ Despite this, since 2008, the US Preventive Services Task Force recommends against the routine screening for BV in asymptomatic pregnant women. For pregnant women at high risk for preterm birth, the evidence is insufficient to make any recommendation about screening. ${ }^{78}$ The Centers for Disease Control and Prevention have made similar recommendations. ${ }^{76}$

Women with BV also have an elevated risk of postoperative infection, especially after surgical abortion in the first trimester. Additional prophylactic antibiotics given to women with asymptomatic BV have not been shown to reduce the risk. As such, evidence to support the usefulness of pre-procedure screening for BV is lacking. ${ }^{79}$ The Society of Family Planning does not recommend routine screening for asymptomatic BV but recommends the routine use of antibiotic prophylaxis, preferably with doxycycline, before surgical abortion.

Current recommendations do not advocate treatment of asymptomatic BV in order to reduce the acquisition of sexually transmitted diseases or HIV. Few studies have investigated the benefit of treatment. The first two randomized studies yielded conflicting results on the impact of screening and treatment of sexually transmitted infections, including $\mathrm{BV}$, to prevent HIV acquisition. ${ }^{80,81}$ However, a pilot study demonstrated that treatment of asymptomatic BV with metronidazole among HIV-infected women had an impact on HIV-1 shedding in the genital tract. ${ }^{82}$ Furthermore, a prospective randomized study suggested that twice-weekly prophylactic use of intravaginal metronidazole gel resulted in significantly fewer cases of chlamydial infection. ${ }^{83}$ Based on these data, consideration should be given to routine treatment of women with asymptomatic BV; however, further studies are warranted to confirm these findings.

\section{Treatment failure}

Unfortunately, relapse is frequent after antibiotic treatment. The recurrence rate has been estimated at 58\% 12 months after oral metronidazole therapy. ${ }^{84}$ There are several possible reasons for the treatment failure. Firstly, the strains of A. vaginae have a variable susceptibility for metronidazole with some even showing a high-level resistance. ${ }^{85}$ Secondly, resistance to antimicrobial agent may be due to the survival of $A$. vaginae and $G$. vaginalis as a biofilm on the vaginal epithelium after therapy. ${ }^{9}$ Lastly, possible reinfection may explain the high recurrence rate as suggested by the highest cure rate observed among women who abstained from having sex or consistently used condoms during treatment. ${ }^{86}$

No recommendations and limited data are available on optimal management strategies for women with recurring BV 
or in whom treatment failed. It appears as though treatment of recurrent BV may require a combination of modalities. ${ }^{87}$ Providers should firstly counsel women with recurrent BV to minimize their number of male sex partners, although few data support recommending other behavioral changes. ${ }^{88}$ Then, in the absence of curative therapy, practitioners should resort to retreating each individual episode of $\mathrm{BV}$ with a different treatment regimen or extending the duration of therapy from a single dose to a 7-day regimen if needed. ${ }^{25,89}$ For women with high risk of recurrence of symptomatic $\mathrm{BV}$, others have suggested suppressive therapy after an initial treatment of BV. Topical boric acid associated with suppressive metronidazole gel or the use of acetic acid vaginal gel has been recommended to keep the vaginal $\mathrm{pH}$ at $\leq 4.5 .{ }^{90,91}$ Similarly, the use of lactic acid gel after an initial metronidazole treatment should reduce the recurrence of symptomatic BV..$^{92}$ Long-term follow-up periods are needed to validate this therapeutic option.

Finally, several studies have evaluated the clinical and microbiological efficacy of probiotics to treat and to prevent the recurrence of BV. Despite the need for more clinical studies, probiotics should be considered as part of the approach to disease prevention, and as an adjunct to antimicrobial treatment. ${ }^{92}$

\section{Conclusion}

Several antimicrobial agents have been used to treat symptomatic BV. Until recently, the mainstay therapy consisted of either metronidazole or clindamycin. A recent alternative has been the use of tinidazole. Probiotics should be seriously considered as part of the approach to disease prevention, and as an adjunct to antimicrobial treatment. Current recommendations do not advocate treatment of asymptomatic BV.

\section{Acknowledgment}

The author thanks Emily Witty for editing the manuscript.

\section{Disclosure}

The author reports no conflicts of interest in this work.

\section{References}

1. Koumans EH, Sternberg M, Bruce C, et al. The prevalence of bacterial vaginosis in the United States, 2001-2004; associations with symptoms, sexual behaviors, and reproductive health. Sex Transm Dis. 2007;34: 864-869.

2. Turovskiy Y, Sutyak Noll K, Chikindas ML. The aetiology of bacterial vaginosis. J Appl Microbiol. 2011;110:1105-1128.

3. Smart S, Singal A, Mindel A. Social and sexual risk factors for bacterial vaginosis. Sex Transm Infect. 2004;80:58-62.
4. Yotebieng M, Turner AN, Hoke TH, Van Damme K, Rasolofomanana JR, Behets F. Effect of consistent condom use on 6-month prevalence of bacterial vaginosis varies by baseline BV status. Trop Med Int Health. 2009; 14:480-456.

5. Gray RH, Kigozi G, Serwadda D, et al. The effects of male circumcision on female partners' genital tract symptoms and vaginal infections in a randomized trial in Rakai, Uganda. Am J Obstet Gynecol. 2009;200: 42. e1-e7.

6. Gardner HL, Dukes CD. Haemophilus vaginalis vaginitis: a newly defined specific infection previously classified non-specific vaginitis. Am J Obstet Gynecol. 1955;69:962-976.

7. Lamont RF, Sobel JD, Akins RA, et al. The vaginal microbiome: new information about genital tract flora using molecular based techniques. BJOG. 2011;118:533-549.

8. Fredricks DN, Fiedler TL, Marrazzo JM. Molecular identification of bacteria associated with bacterial vaginosis. N Engl J Med. 2005;353: 1899-1911.

9. Swidsinski A, Mendling W, Loening-Baucke V, et al. An adherent Gardnerella vaginalis biofilm persists on the vaginal epithelium after standard therapy with oral metronidazole. Am J Obstet Gynecol. 2008; 198:97. e1-e6.

10. Menard JP, Fenollar F, Henry M, Bretelle F, Raoult D. Molecular quantification of Gardnerella vaginalis and Atopobium vaginae loads to predict bacterial vaginosis. Clin Infect Dis. 2008;47:33-43.

11. Amsel R, Totten PA, Spiegel CA, Chen KC, Eschenbach D, Holmes KK. Nonspecific vaginitis. Diagnostic criteria and microbial and epidemiologic associations. Am J Med. 1983;74:14-22.

12. Nugent RP, Krohn MA, Hillier SL. Reliability of diagnosing bacterial vaginosis is improved by a standardized method of gram stain interpretation. J Clin Microbiol. 1991;29:297-301.

13. Brotman RM, Klebanoff MA, Nansel TR, et al. Bacterial vaginosis assessed by gram stain and diminished colonization resistance to incident gonococcal, chlamydial, and trichomonal genital infection. J Infect Dis. 2010;202:1907-1915.

14. Allsworth JE, Lewis VA, Peipert JF. Viral sexually transmitted infections and bacterial vaginosis: 2001-2004 National Health and Nutrition Examination Survey data. Sex Transm Dis. 2008;35: 791-796.

15. Larsson PG, Platz-Christensen JJ, Thejls H, Forsum U, Påhlson C. Incidence of pelvic inflammatory disease after first-trimester legal abortion in women with bacterial vaginosis after treatment with metronidazole: a double-blind, randomized study. Am J Obstet Gynecol. 1992;166:100-103.

16. Svare JA, Schmidt H, Hansen BB, Lose G. Bacterial vaginosis in a cohort of Danish pregnant women: prevalence and relationship with preterm delivery, low birthweight and perinatal infections. BJOG. 2006;113:1419-1425.

17. US Department of Health and Human Services, Food and Drug Administration, Center for Drug Evaluation and Research (1998). Available at: http://www.fda.gov/downloads/Drugs/GuidanceComplianceRegulatoryInformation/Guidances/ucm070969.pdf. Accessed July 22, 2011.

18. Löfmark S, Edlund C, Nord CE. Metronidazole is still the drug of choice for treatment of anaerobic infections. Clin Infect Dis. 2010; 50(Suppl 1):S16-S23.

19. Koumans EH, Markowitz LE, Hogan V; CDC BV Working Group. Indications for therapy and treatment recommendations for bacterial vaginosis in nonpregnant and pregnant women: a synthesis of data. Clin Infect Dis. 2002;35:S152-S172.

20. Oduyebo OO, Anorlu RI, Ogunsola FT. The effects of antimicrobial therapy on bacterial vaginosis in non-pregnant women. Cochrane Database Syst Rev. 2009;3:CD006055.

21. Hanson JM, McGregor JA, Hillier SL, et al. Metronidazole for bacterial vaginosis. A comparison of vaginal gel vs oral therapy. J Reprod Med. 2000;45:889-896.

22. Ransom SB, McComish JF, Greenberg R, Tolford DA. Oral metronidazole vs Metrogel Vaginal for treating bacterial vaginosis. Cost-effectiveness evaluation. J Reprod Med. 1999;44:359-362. 
23. Lugo-Miro VI, Green M, Mazur L. Comparison of different metronidazole therapeutic regimens for bacterial vaginosis. A meta-analysis. JAMA. 1992;268:92-95.

24. Joesoef MR, Schmid GP, Hillier SL. Bacterial vaginosis: review of treatment options and potential clinical indications for therapy. Clin Infect Dis. 1999;28 Suppl 1:S57-S65.

25. Schwebke JR, Desmond RA. A randomized trial of the duration of therapy with metronidazole plus or minus azithromycin for treatment of symptomatic bacterial vaginosis. Clin Infect Dis. 2007;44:213-219.

26. Brandt M, Abels C, May T, Lohmann K, Schmidts-Winkler I, Hoyme UB. Intravaginally applied metronidazole is as effective as orally applied in the treatment of bacterial vaginosis, but exhibits significantly less side effects. Eur J Obstet Gynecol Reprod Biol. 2008;141:158-162.

27. Mikamo H, Kawazoe K, Izumi K, Watanabe K, Ueno K, Tamaya T. Comparative study on vaginal or oral treatment of bacterial vaginosis. Chemotherapy. 1997;43:60-68.

28. Sobel J, Peipert JF, McGregor JA, et al. Efficacy of clindamycin vaginal ovule (3-day treatment) vs clindamycin vaginal cream (7-day treatment) in bacterial vaginosis. Infect Dis Obstet Gynecol. 2001;9:9-15.

29. Faro S, Skokos CK; Clindesse Investigators Group. The efficacy and safety of a single dose of Clindesse vaginal cream versus a seven-dose regimen of Cleocin vaginal cream in patients with bacterial vaginosis. Infect Dis Obstet Gynecol. 2005;13:155-160.

30. Ekgren J, Norling BK, Degre M, Midtvedt T. Comparison of tinidazole given as a single dose and on 2 consecutive days for the treatment of nonspecific bacterial vaginosis. Gynecol Obstet Invest. 1988;26: 313-317.

31. Food and Drug Administration. Available at: http://www.accessdata. fda.gov/drugsatfda_docs/label/2007/021618s0031bl.pdf. Accessed July 22, 2011.

32. Livengood CH, Ferris DG, Wiesenfeld HC, et al. Effectiveness of two tinidazole regimens in treatment of bacterial vaginosis: a randomized controlled trial. Obstet Gynecol. 2007;110:302-309.

33. Armstrong NR, Wilson JD. Tinidazole in the treatment of bacterial vaginosis. Int J Womens Health. 2010;1:59-65.

34. Schwebke JR, Desmond RA. Tinidazole vs metronidazole for the treatment of bacterial vaginosis. Am J Obstet Gynecol. 2011;204: 211. e1-e6.

35. Milani M, Barcellona E, Agnello A. Efficacy of the combination of $2 \mathrm{~g}$ oral tinidazole and acidic buffering vaginal gel in comparison with vaginal clindamycin alone in bacterial vaginosis: a randomized, investigator-blinded, controlled trial. Eur J Obstet Gynecol Reprod Biol. 2003;109:67-71.

36. Gillis JC, Wiseman LR. Secnidazole. A review of its antimicrobial activity, pharmacokinetic properties and therapeutic use in the management of protozoal infections and bacterial vaginosis. Drugs. 1996;51:621-638.

37. Bohbot JM, Vicaut E, Fagnen D, Brauman M. Treatment of bacterial vaginosis: a multicenter, double-blind, double-dummy, randomised phase III study comparing secnidazole and metronidazole. Infect Dis Obstet Gynecol. 2010;2010. pii: 705692.

38. Núñez JT, Gómez G. Low-dose secnidazole in the treatment of bacterial vaginosis. Int J Gynaecol Obstet. 2005;88:281-285.

39. Narayana RC, Harish NM, Gulzar AM, Prabhakara P, Singh AK, Subrahmanyam EV. Formulation and in vitro evaluation of in situ gels containing secnidazole for vaginitis. Yakugaku Zasshi. 2009;129: 569-574.

40. Food and Drug Administration, World Health Organization (2001). Available at: http://www.who.int/foodsafety/publications/ fs_management/en/probiotics.pdf. Accessed July 22, 2011.

41. Howard JC, Heinemann C, Thatcher BJ, Martin B, Gan BS, Reid G. Identification of collagen-binding proteins in Lactobacillus spp. with surface-enhanced laser desorption/ionization-time of flight proteinchip technology. Appl Environ Microbiol. 2000;66:4396-4400.

42. Pascual LM, Daniele MB, Ruiz F, Giordano W, Pajaro C, Barberis L. Lactobacillus rhamnosus L60, a potential probiotic isolated from the human vagina. J Gen Appl Microbiol. 2008;54:141-148.
43. Sheil B, Shanahan F, O’Mahony L. Probiotic effects on inflammatory bowel disease. J Nutr. 2007;137:819S-824S.

44. Reid G, Beuerman D, Heinemann C, Bruce AW. Probiotic Lactobacillus dose required to restore and maintain a normal vaginal flora. FEMS Immunol Med Microbiol. 2001;32:37-41.

45. Reid G, Charbonneau D, Erb J, et al. Oral use of Lactobacillus rhamnosus GR-1 and L. fermentum RC-14 significantly alters vaginal flora: randomized, placebo-controlled trial in 64 healthy women. FEMS Immunol Med Microbiol. 2003;35:131-134.

46. Hemmerling A, Harrison W, Schroeder A, et al. Phase 2a study assessing colonization efficiency, safety, and acceptability of Lactobacillus crispatus CTV-05 in women with bacterial vaginosis. Sex Transm Dis. 2010;37:745-750.

47. Petricevic L, Witt A. The role of Lactobacillus casei rhamnosus Lcr 35 in restoring the normal vaginal flora after antibiotic treatment of bacterial vaginosis. BJOG. 2008;115:1369-1374.

48. Ruiz FO, Gerbaldo G, Asurmendi P, Pascual LM, Giordano W, Barberis IL. Antimicrobial activity, inhibition of urogenital pathogens, and synergistic interactions between lactobacillus strains. Curr Microbiol. 2009;59:497-501.

49. Senok AC, Verstraelen H, Temmerman M, Botta GA. Probiotics for the treatment of bacterial vaginosis. Cochrane Database Syst Rev. 2009;4: CD006289.

50. Falagas ME, Betsi GI, Athanasiou S. Probiotics for the treatment of women with bacterial vaginosis. Clin Microbiol Infect. 2007;13: 657-664.

51. Anukam KC, Osazuwa E, Osemene GI, Ehigiagbe F, Bruce AW, Reid G. Clinical study comparing probiotic Lactobacillus GR-1 and RC-14 with metronidazole vaginal gel to treat symptomatic bacterial vaginosis. Microbes Infect. 2006;8:2772-2776.

52. Donders GG, Van Bulck B, Van de Walle P, et al. Effect of lyophilized lactobacilli and $0.03 \mathrm{mg}$ estriol $\left(\mathrm{Gynoflor}^{\mathbb{B}}\right.$ ) on vaginitis and vaginosis with disrupted vaginal microflora: a multicenter, randomized, singleblind, active-controlled pilot study. Gynecol Obstet Invest. 2010;70: 264-272.

53. Anukam K, Osazuwa E, Ahonkhai I, et al. Augmentation of antimicrobial metronidazole therapy of bacterial vaginosis with oral probiotic Lactobacillus rhamnosus GR-1 and Lactobacillus reuteri RC-14: randomized, double-blind, placebo controlled trial. Microbes Infect. 2006;8:1450-1454.

54. Martinez RC, Franceschini SA, Patta MC, et al. Improved cure of bacterial vaginosis with single dose of tinidazole $(2 \mathrm{~g})$, Lactobacillus rhamnosus GR-1, and Lactobacillus reuteri RC-14: a randomized, double-blind, placebo-controlled trial. Can J Microbiol. 2009;55:133-138.

55. Hummelen R, Changalucha J, Butamanya NL, Cook A, Habbema JD, Reid G. Lactobacillus rhamnosus GR-1 and L. reuteri RC-14 to prevent or cure bacterial vaginosis among women with HIV. Int J Gynaecol Obstet. 2010;111:245-248.

56. Larsson PG, Stray-Pedersen B, Ryttig KR, Larsen S. Human lactobacilli as supplementation of clindamycin to patients with bacterial vaginosis reduce the recurrence rate; a 6-month, double-blind, randomized, placebo-controlled study. BMC Womens Health. 2008;8:3.

57. Marcone V, Rocca G, Lichtner M, Calzolari E. Long-term vaginal administration of Lactobacillus rhamnosus as a complementary approach to management of bacterial vaginosis. Int J Gynaecol Obstet. 2010;110:223-226.

58. Ya W, Reifer C, Miller LE. Efficacy of vaginal probiotic capsules for recurrent bacterial vaginosis: a double-blind, randomized, placebocontrolled study. Am J Obstet Gynecol. 2010;203:120. e1-e6.

59. Holley RL, Richter HE, Varner RE, Pair L, Schwebke JR. A randomized, double-blind clinical trial of vaginal acidification versus placebo for the treatment of symptomatic bacterial vaginosis. Sex Transm Dis. 2004;31:236-238.

60. Simoes JA, Bahamondes LG, Camargo RP, et al. A pilot clinical trial comparing an acid-buffering formulation (ACIDFORM gel) with metronidazole gel for the treatment of symptomatic bacterial vaginosis. Br J Clin Pharmacol. 2006;61:211-217. 
61. Decena DC, Co JT, Manalastas RM Jr, et al. Metronidazole with Lactacyd vaginal gel in bacterial vaginosis. J Obstet Gynaecol Res. 2006;32:243-251.

62. Shaaban OM, Fetih GN, Abdellah NH, Ismail S, Ibrahim MA, Ibrahim ES. Pilot randomized trial for treatment of bacterial vaginosis using in situ forming metronidazole vaginal gel. J Obstet Gynaecol Res. 2011;37:874-881.

63. Perioli L, Ambrogi V, Pagano C, Scuota S, Rossi C. FG90 chitosan as a new polymer for metronidazole mucoadhesive tablets for vaginal administration. Int J Pharm. 2009;377:120-127.

64. Dobaria N, Mashru R. Design and in vitro evaluation of a novel bioadhesive vaginal drug delivery system for clindamycin phosphate. Pharm Dev Technol. 2010;15:405-414.

65. Mendling W, Mailland F. Microbiological and pharmaco-toxicological profile of nifuratel and its favourable risk/benefit ratio for the treatment of vulvo-vaginal infections. A review. Arzneimittelforschung. 2002; $52: 8-13$.

66. Togni G, Battini V, Bulgheroni A, Mailland F, Caserini M, Mendling W. In vitro activity of nifuratel on vaginal bacteria: could it be a good candidate for the treatment of bacterial vaginosis? Antimicrob Agents Chemother. 2011;55:2490-2492.

67. Donders G, Bellen G, Ausma J, et al. The effect of antifungal treatment on the vaginal flora of women with vulvo-vaginal yeast infection with or without bacterial vaginosis. Eur J Clin Microbiol Infect Dis. 2011;30: 59-63.

68. Sanchez S, Garcia PJ, Thomas KK, Catlin M, Holmes KK. Intravaginal metronidazole gel versus metronidazole plus nystatin ovules for bacterial vaginosis: a randomized controlled trial. Am J Obstet Gynecol. 2004;191:1898-1906.

69. Braga PC, Dal Sasso M, Culici M, Spallino A. Inhibitory activity of thymol on native and mature Gardnerella vaginalis biofilms: in vitro study. Arzneimittelforschung. 2010;60:675-681.

70. Sosto F, Benvenuti C; CANVA Study Group. Controlled study on thymol + eugenol vaginal douche versus econazole in vaginal candidiasis and metronidazole in bacterial vaginosis. Arzneimittelforschung. 2011;61:126-131

71. Strandberg KL, Peterson ML, Lin YC, Pack MC, Chase DJ, Schlievert PM. Glycerol monolaurate inhibits Candida and Gardnerella vaginalis in vitro and in vivo but not Lactobacillus. Antimicrob Agents Chemother. 2010;54:597-601.

72. Novakov Mikic A, Budakov D. Comparison of local metronidazole and a local antiseptic in the treatment of bacterial vaginosis. Arch Gynecol Obstet. 2010;282:43-47.

73. Chen M, Pan X, Wu H, et al. Preparation and anti-bacterial properties of a temperature-sensitive gel containing silver nanoparticles. Pharmazie. 2011;66:272-277.

74. Rousseau V, Lepargneur JP, Roques C, Remaud-Simeon M, Paul F. Prebiotic effects of oligosaccharides on selected vaginal lactobacilli and pathogenic microorganisms. Anaerobe. 2005;11:145-153.

75. Zeng ZM, Liao QP, Yao C, et al. Directed shift of vaginal flora after topical application of sucrose gel in a phase III clinical trial: a novel treatment for bacterial vaginosis. Chin Med J. 2010;123:2051-2057.

76. US Centers for Disease Control and Prevention Sexually Transmitted Diseases Treatment Guidelines 2010. Available at: http://www.cdc. gov/mmwr/pdf/rr/rr5912.pdf. Accessed July 22, 2011.
77. McDonald HM, Brocklehurst P, Gordon A. Antibiotics for treating bacterial vaginosis in pregnancy. Cochrane Database Syst Rev. 2007;1: CD000262.

78. Nygren P, Fu R, Freeman M, et al. Evidence on the benefits and harms of screening and treating pregnant women who are asymptomatic for bacterial vaginosis: an update review for the US Preventive Services Task Force. Ann Intern Med. 2008;148:220-233.

79. Achilles SL, Reeves MF; Society of Family Planning. Prevention of infection after induced abortion: release date October 2010: SFP guideline 20102 .

80. Wawer MJ, Sewankambo NK, Serwadda D, et al. Control of sexually transmitted diseases for AIDS prevention in Uganda: a randomised community trial. Rakai Project Study Group. Lancet. 1999;353: $525-535$.

81. Grosskurth H, Mosha F, Todd J, et al. Impact of improved treatment of sexually transmitted diseases on HIV infection in rural Tanzania: randomised controlled trial. Lancet. 1995;346:530-536.

82. Moreira C, Venkatesh KK, DeLong A, et al. Effect of treatment of asymptomatic bacterial vaginosis on HIV-1 shedding in the genital tract among women on antiretroviral therapy: a pilot study. Clin Infect Dis. 2009;49:991-992.

83. Schwebke JR, Desmond R. A randomized trial of metronidazole in asymptomatic bacterial vaginosis to prevent the acquisition of sexually transmitted diseases. Am J Obstet Gynecol. 2007;196:517. e1-e6.

84. Bradshaw CS, Tabrizi SN, Fairley CK, Morton AN, Rudland E, Garland SM. The association of Atopobium vaginae and Gardnerella vaginalis with bacterial vaginosis and recurrence after oral metronidazole therapy. J Infect Dis. 2006;194:828-836.

85. De Backer E, Verhelst R, Verstraelen H, et al. Antibiotic susceptibility of Atopobium vaginae. BMC Infect Dis. 2006;6:51.

86. Bradshaw CS, Morton AN, Hocking J. High recurrence rates of bacterial vaginosis over the course of 12 months after oral metronidazole therapy and factors associated with recurrence. J Infect Dis. 2006;193: 1478-1486.

87. Hay P. Recurrent bacterial vaginosis. Curr Opin Infect Dis. 2009;22 82-86.

88. Klatt TE, Cole DC, Eastwood DC, Barnabei VM. Factors associated with recurrent bacterial vaginosis. J Reprod Med. 2010;55:55-61.

89. Bunge KE, Beigi RH, Meyn LA, Hillier SL. The efficacy of retreatment with the same medication for early treatment failure of bacterial vaginosis. Sex Transm Dis. 2009;36:711-713.

90. Reichman O, Akins R, Sobel JD. Boric acid addition to suppressive antimicrobial therapy for recurrent bacterial vaginosis. Sex Transm Dis. 2009;36:732-734

91. Wilson JD, Shann SM, Brady SK, Mammen-Tobin AG, Evans AL, Lee RA. Recurrent bacterial vaginosis: the use of maintenance acidic vaginal gel following treatment. Int J STD AIDS. 2005;16:736-738.

92. MacPhee RA, Hummelen R, Bisanz JE, Miller WL, Reid G. Probiotic strategies for the treatment and prevention of bacterial vaginosis. Expert Opin Pharmacother. 2010;11:2985-2995.
International Journal of Women's Health

\section{Publish your work in this journal}

The International Journal of Women's Health is an international, peerreviewed open-access journal publishing original research, reports, reviews and commentaries on all aspects of women's healthcare including gynecology, obstetrics, and breast cancer. Subject areas include: Chronic conditions (migraine headaches, arthritis, osteoporosis);

\section{Dovepress}

Endocrine and autoimmune syndromes; Sexual and reproductive health; Psychological and psychosocial conditions. The manuscript management system is completely online and includes a very quick and fair peer-review system. Visit http://www.dovepress.com/ testimonials.php to read real quotes from published authors. 